\title{
Designing Web Based Offering and Sales Information System (Case Study : PT. Daya Berkah Sentosa Nusantara)
}

\section{Perancangan Sistem Informasi Penawaran dan Penjualan Berbasis Web (Studi Kasus : PT. Daya Berkah Sentosa Nusantara)}

\author{
$1^{\text {st }}$ Siti Nurjanah Ramadhany ${ }^{1}, 2^{\text {nd }}$ Ade Eviyanti ${ }^{2}$ \\ \{dhanyrama882@gmail.com ${ }^{1}$, adeeviyanti@ umsida.ac.id ${ }^{2}$ \} \\ Universitas Muhammadiyah Sidoarjo, Indonesia ${ }^{1}$, Universitas Muhammadiyah Sidoarjo, Indonesia ${ }^{2}$
}

\begin{abstract}
Technology is increasingly sophisticated with over time competition in the business world such as E-Commerce has a positive impact on entrepreneurs to advance their companies, namely by creating online websites so that offerings and sales are easy among the public. By accessing the website page of PT. Daya Berkah Sentosa Nusantara buyers do not have to come directly to the place or company, and send offers according to admin needs.The purpose of this study is to make it easier for researchers to solve supply and sales problems based on problems that arise in the company. The method used in this study is the Waterfall Method, with data collection techniques used using observation, interviews and literature study. The desired result of this research is to be able to create a website for the company, to be able to expand marketing reach, buyers can view products through the website.
\end{abstract}

Keywords - Sales; Buying; Information; Website

\begin{abstract}
Abstrak. Teknologi semakin canggih dengan seiring waktu persaingan di dunia bisnis seperti E-Commerce membawa dampak positif bagi para pengusaha untuk memajukan perusahaannya yaitu dengan membuat website online agar penawaran dan penjualan mudah dikalangan masyarakat. Dengan mengakses halaman website PT. Daya Berkah Sentosa Nusantara pembeli tidak harus datang langsung ketempat atau perusahaan, dan mengirim penawaran sesuai dengan kebutuhan admin. Tujuan dari penelitian ini adalah Memudahkan Peneliti untuk Menyelesaikan masalah penawaran dan penjualan berdasarkan masalah yang muncul pada perusahaan. Metode yang digunakan pada penelitian ini adalah Metode Waterfall, dengan teknik pengumpulan data yang digunakan menggunakan observasi, wawancara dan studi pustaka. Hasil yang diinginkan dari Penelitian ini adalah dapat membuat website untuk perusahaan, dapat memperluas jangkauan pemasaran, pembeli dapat melihat produk melalui website.
\end{abstract}

Kata Kunci - Penjualan; Pembelian; Informasi; Website

\section{Pendahuluan}

E-Commerce merupakan melakukan pemasaran secara iklan, melakukan penjualan dan melakukan bantuan pelayanan yang terbaik dengan menggunakan sebuah web usaha 24 jam setiap hari untuk seluruh pembeli yang dilakukan kepada suatu jaringan internet ${ }^{[1]}$. Dengan memanfaatkan dan menggunakan internet yang diharapkan mampu untuk memberikan manfaat yang sangat besar untuk dunia persaingan bisnis ${ }^{[2]}$. Perusahaan dapat bersaing dalam persaingan merupakan perusahaan yang dapat memanfaatkan internet kedalam perusahaannya.

Sistem informasi adalah sistem di dalam sebuah organisasi yang mempertemukan kebutuhan pengolahan transaksi setiap hari yang mendukung fungsi organisasi yang bersifat manajerial dengan kegiatan strategi dari suatu organisasi untuk dapat menyediakan kepada pihak luar tertentu dengan laporan- laporan yang dibutuhkan ${ }^{[3]}$.

Penjualan adalah kegiatan transaksi antara penjual dan pembeli yang akan menjual produk atau jasa dan mengaharapkan akan mendapatkan keuntungan dari kegiatan transaksi tersebut dan bias disebut pengalihan hak kepemilikan barang dari penjual ke pembeli ${ }^{[4]}$. Penawaran adalah jenis produk yang akan dan dapat untuk ditawarkan penjual ke pembeli untuk berbagai tingkatan waktu dan harga.Penawaran menggambarkan interaksi secara langsung antara produk dan kapasitas, bunyi hokum penawaran mengatakan jika harga produk tinggi penjual ingin menawarkan lebih banyak lagi produk ke pembeli ${ }^{[5]}$.

Masalah yang dihadapi oleh perusahaan PT. Daya Berkah Sentosa Nusantara membutuhkan adanya sebuah website. Website sangat penting karena dapat membantu penyampaian rincian spesifikasi produk dan harga secara detail kepada pembeli. Dengan adanya website, informasi dapat diakses jika dibutuhkan. Dan website menampilkan proses perusahaan melakukan penjualan sehingga menampilkan tampilkan penawaran produk dan penjelasan produk.

Menurut ${ }^{[6]}$., website atau situs adalah sebuah kumpulan halaman yang menyajikan bermacam-macam informasi yang dapat berupa data teks, data gambar diam, gambar bergerak, animasi, suara, video ataupun gabungan dari 
semuanya yang membentuk satu rangkaian yang saling berhubungan. Pengujian dalam perangkat lunak dilakukan agar dapat mendeteksi jika terjadi kesalahan, yang mengakibatkan kegagalan perangkat lunak.Tetapi, pengujian dalam perangkat lunak merupakan tugas yang memakan waktu.Tahapan pengujian akan mampu menghabiskan sekitar 50\% sumber daya pengembangan perangkat lunak.Pengujian perangkat lunak merupakan sebuah proses verifikasi dan validasi pada perangkat lunak yang bertujuan memastikan bahwa sebuah apilkasi telah memenuhi persyaratan teknis dan bisnis yang diharapkan. ${ }^{[7]}$.

UAT (User Acceptance Testing) merupakan kumpulan beberapa langkah untuk pengujian pada aplikasi pada pengguna, dengan menggunakan format yang telah disepakati dari awal secara bersama, yang bertujuan untuk mengetahui seberapa jauh pengguna memahami aplikasi yang sudah disajikan, dan apakah web aplikasi telah mampu untuk memenuhi kebutuhan pengguna dan dapat menyelesaikan masalah yang terjadi, dengan hasil yang akhir sebuah dokumen yang lengkap dalam pengembangan aplikasi ${ }^{[8]}$.

Blackbox Testing merupakan suatu pengujian perangkat lunak yang merupakan tes fungsionalitas dari aplikasi yang tidak sesuai pada struktur internal atau tidak lagi membutuhkan pengetahuan yang sangat khusus untuk kode pemrograman aplikasi dan pengetahuan oleh pengguna.Dalam ujicoba Blackbox yang dilakukan dapat menemukan beberapa kesalahan seperti : Fungsi tombol yang tidak sesuai, Kesalahan desain tampilan, Kesalahan database, dan kesalahan inisialisasi dan terminasi. ${ }^{[9]}$.

\section{METODE}

\section{A. Lokasi dan Waktu Penelitian}

Penelitian ini akan dilakukan di Kompleks Pergudangan dan Industri Kencana Trosobo, Blok B7 Jl. Raya Trosobo KM23 Kecamatan Tama, Kabupaten.Sidoarjo (Depan Pabrik Aneka Coffee). Penelitian ini dilakukan mulaiBulan Oktober 2020

\section{B. Analisa Masalah}

PT. Daya Berkah Sentosa Nusantara merupakan usaha yang bergerak dalam bidang pembangkit listrik tenaga surya dan sedang menampilkan produk-produk peralatan kebutuhan pembangkit listrik tenaga surya dan energi terbarukan, oleh sebab itu PT. Daya Berkah Sentosa Nusantara mengoptimalkan pelayanan yang mudah kepada pembeli, memperluas pemasaran dan produktif dalam meningkatkan penjualannya. Tetapi masalah yang dihadapi PT. Daya Berkah Sentosa Nusantara adalah sistem penawaran dan penjualannya masih dilakukan melalui email atau dilakukan transaksi penjualan secara langsung antara pembeli dan pihak penjual.

\section{Perancangan Sistem}

Pada perancangan arsitektur sistem informasi terdiri dari user (pembeli) menggunakan media browser, web server untuk media penyedia layanan php dan database yang saling terhubung. Simulasi menggunakan internet dan admin melakukan update data.

Gambar 1. Arsitektur Sistem

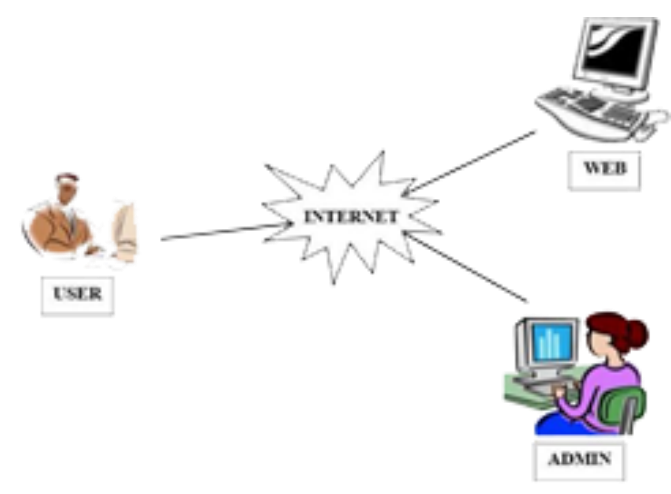




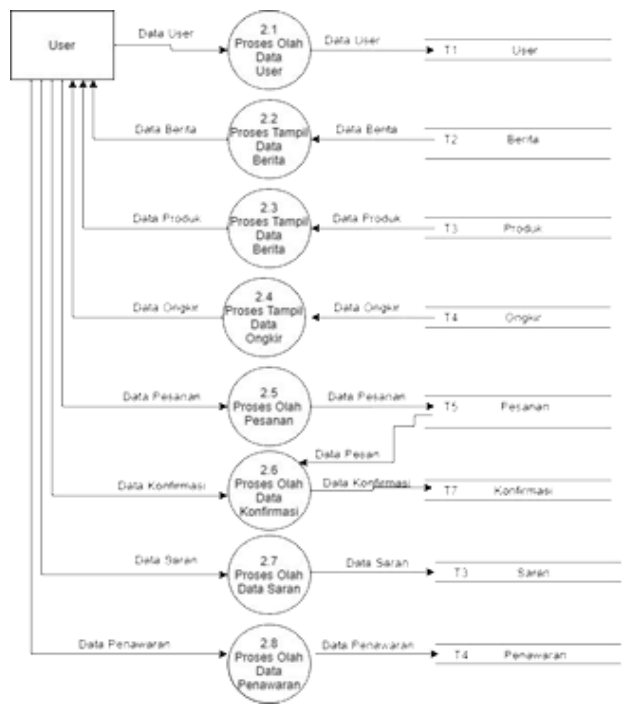

Gambar 2. DFD Level 1 Proses User

Penjelasan :

DFD Level 1 diatas menjelaskan pengembangan dari DFD Level 0. Terdapat dua entitas yaitu user dan admin. Proses input user antara lain input data user (pendaftaran), input data pemesanan, input data saran, input data penawaran, dan input data konfirmasi pembayaran. Selain input user, user dapat melihat tampilan informasi seperti data pengiriman, data produk, data tipe produk, data ongkir, dan data berita. Sedangkan admin dapat menerima data input user dan memprosesnya. Entity Relation Diagram Merupakan kerangka yang berisi sebuah komponen dari entitas dan himpunan relasi yang dilengkapi oleh atribut dan menunjukan fakta yang akan dihubungkan antara entitas yang ada dengan atributnya. ERD dapat menggambarkan suatu hubungan pada pengolahan data seperti one to one, one to many, many to many ${ }^{[10]}$.

\section{Rancangan Antarmuka}

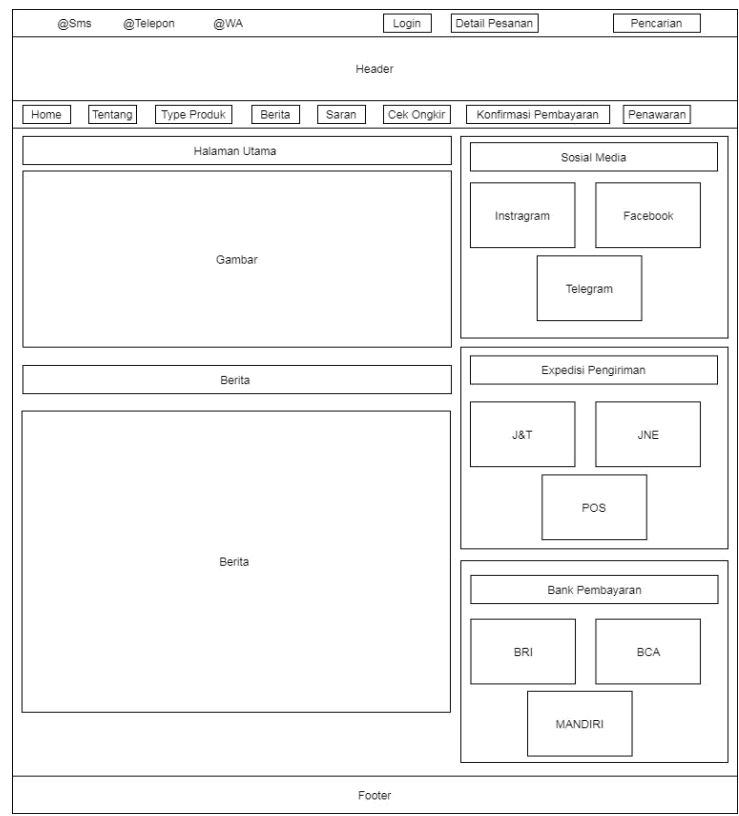

Gambar 3. Rancangan Halaman Utama 
Memasuki halaman ini disaat pertama kali menggunakan sistem ini. Halaman ini disediakan tombol tombol berpindah halaman yaitu tombol home, tentang, type produk, berita, saran, sek ongkir, konfirmasi pembayaran, penawaran, detail pesanan dan login.

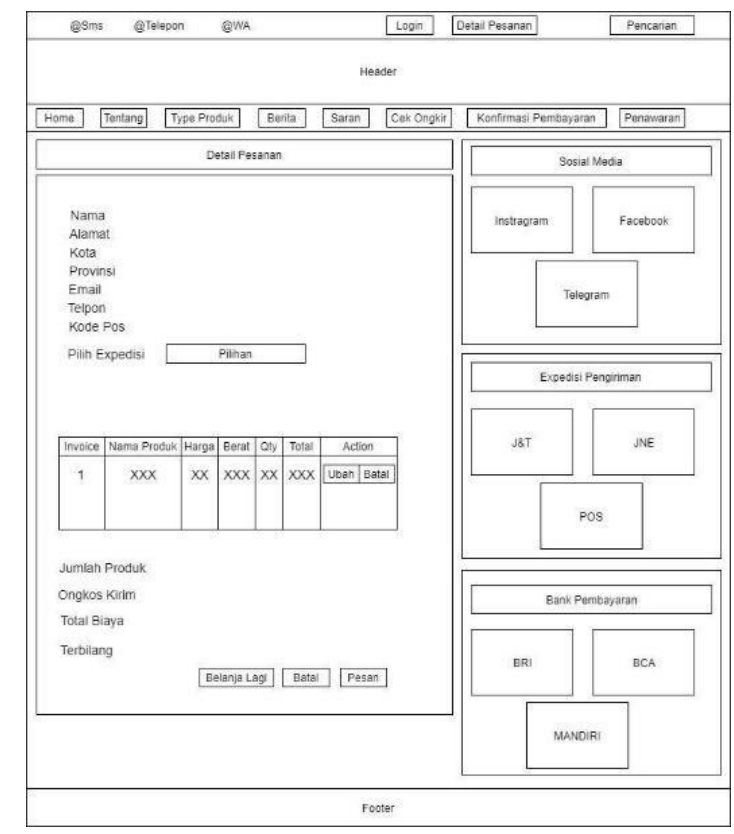

Gambar 4. Halaman Detail Pesanan

Halaman user dapat melakukan pengecekan terhadap pesanan yang akan di pesan, sebelum melakukan pembelian. Halaman ini memberikan informasi jumlah produk, ongkos kirim, total pembayaran, nama, dan pilhan expedisi

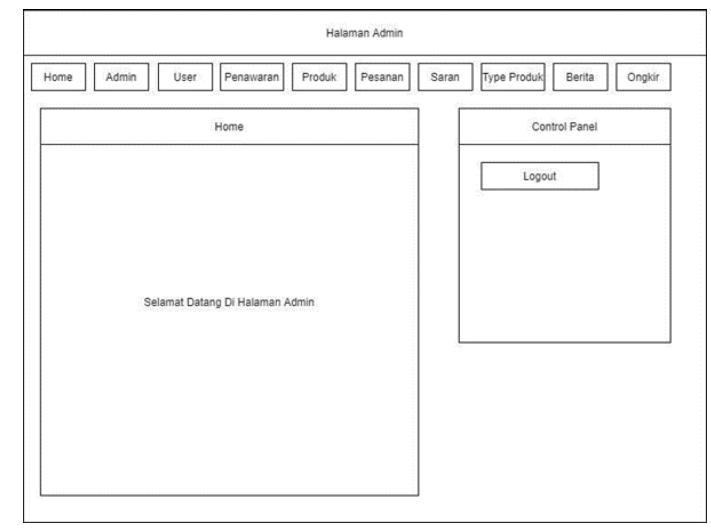

Gambar 5. Arsitektur Sistem

Halaman ini bisa diakses oleh admin. Halaman ini disediakan untuk tombol admin, user, produk, ongkir, pesanan, berita, saran dan penawaran.

\section{HASIL DAN PEMbahasan}

\section{A. Implementasi Antar Muka Admin}

Halaman Administrator merupakan halaman dashboard yang ditampilkan untuk melakukan pengelolaan sistem agar lebih berkembang lagi. Pada web aplikasi administrator memiliki hak untuk mengakses seluruh sistem web aplikasi ini. 
Disini sistem ini dibuat untuk beberapa menu sederhana agar pengguna tidak terlalu rumit ketika menggunakan sistem web aplikasi.Diantaranya Home, Password Admin, Data Ongkir, Data Kategori, Data Barang, Data Berita, Data Saran, Data Pelanggan, Pemesanan Barang, Konfirmasi Transfer, Penawaran, Laporan, dan Logout.

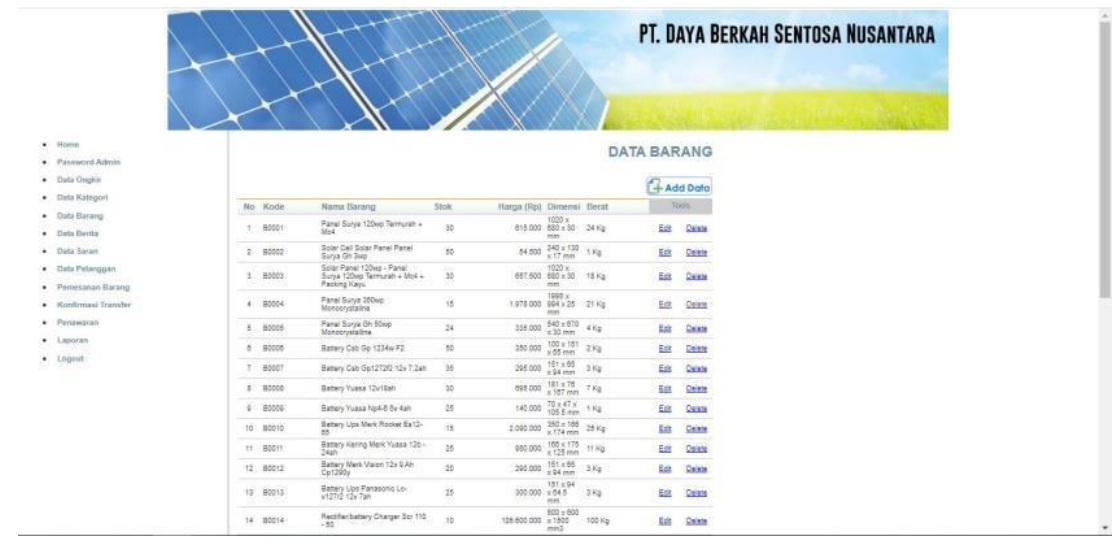

Gambar 7. Halaman Menu Kelola Barang

Tampilan Kelola Barang pada menu admin digunakan untuk menambahkan, mengedit dan menghapus data barang untuk pembeli.Kelola barang dapat mempermudah pembeli dalam melihat spesifikasi barang.Dengan adanya menu kelola barang admin dapat menambahkan produk barang untuk dijual, mengedit apabila ada kesalahan pada pengisian detail produk, dan menghapus produk apabila tidak dijual lagi.

\section{B. Implementasi Antar Muka User}

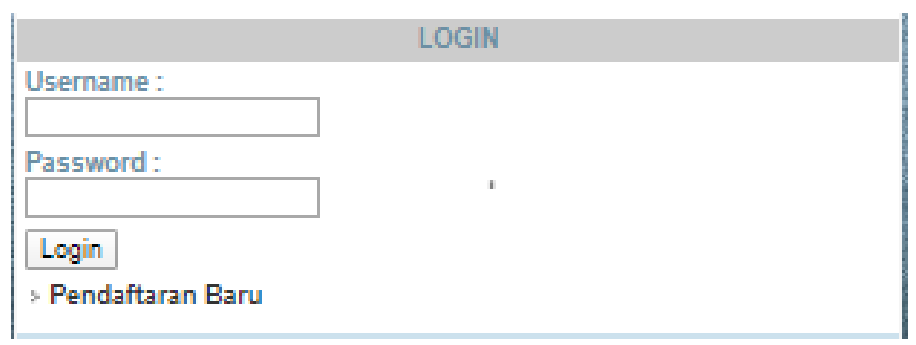

Gambar 8. Arsitektur Sistem

Tampilan Menu Login User digunakan untuk pembeli melakukan login sesuai dengan pendaftaran sebelumnya.Login user merupakan tahapan pertama kali sebelum menggunakan web aplikasi. Menu login user 
hanya dapat dilakukan apabila pembeli sudah melakukan pendaftaran dengan baik dan benar.Menu login dengan memasukkan Username dan Password yang benar, setelah itu akan masuk ke tampilan pembeli sebenarnya.

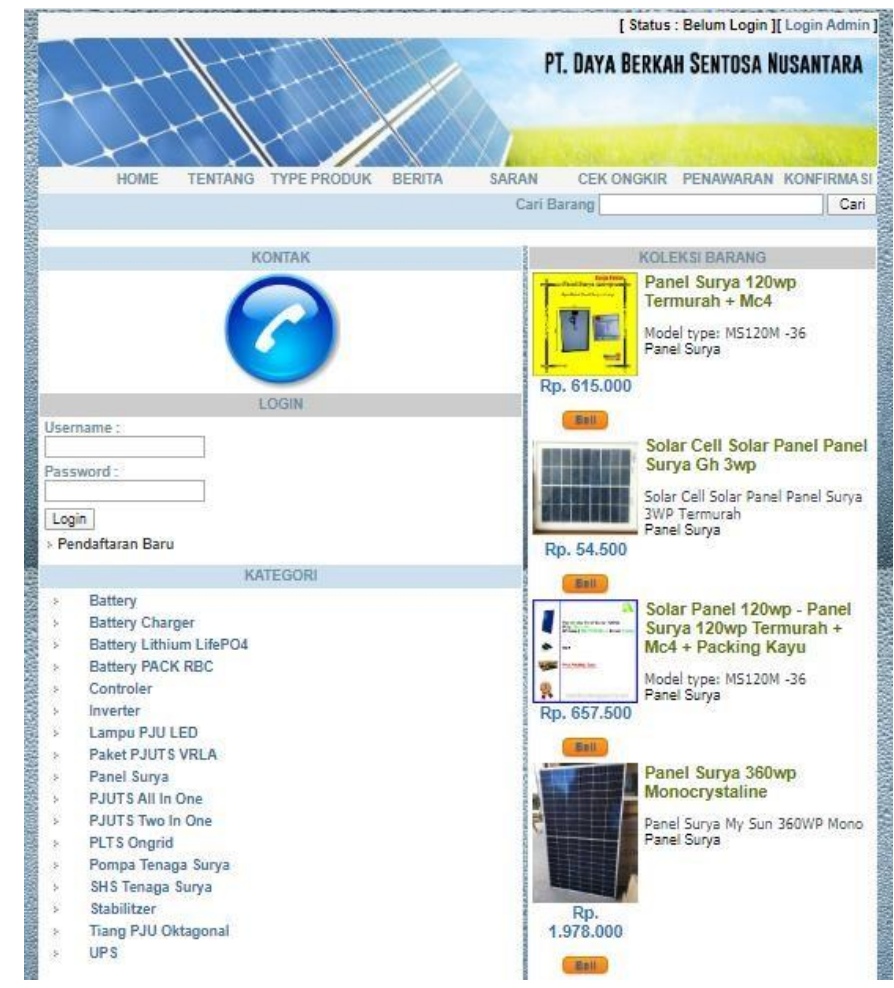

Gambar 9. Tampilan Halaman Utama Admin

Tampilan Menu Halaman Utama digunakan untuk tampilan depan dari web penjualan dan beberapa menu yang bisa diakses pembeli.Halaman utama dapat diakses apabila pembeli sudah melakukan pendaftaran dan login dengan benar. Halaman utama merupakan tampilan utama ketika pembeli akan menggunakan web aplikasi.Halaman utama yang pertama kali dilihat adalah kategori barang, beberapa barang, dan berita.

\section{KESIMPULAN}

Berdasarkan dari hasil yang telah dilakukan dan mendapatkan kesimpulan yang didapat adalah meskipun menggunakan website tetapi akses penjualan dan penawaran dalam website hanya untuk wilayah sidoarjo dan Surabaya tetapi meskipun begitu website pemasaran ini akan menjadi awal dari cara kemajuan cara penjualan dan penawaran pada PT. Daya Berkah Sentosa Nusantara dan dapat mempermudah untuk melakukan transaksi penjualandan mengirimkan penawaran dan mengurangi kerumunan karena pembeli tidak perlu datang ke kantor jika ingin membeli produk.

\section{UCAPAN TERIMA KASIH}

Penulis mengucapkan terimakasih kepada semua pihak yang terkait dan yang sudah membantu dalam melakukan penulisan artikel ilmiah yang berjudul Sistem Informasi Penjualan dan Penawaran pada PT. Daya Berkah Sentosa Nusantara berbasis Web. 
Procedia of Engineering and Life Science Vol. 1. No. 2 Juni 2021

Seminar Nasional \& Call Paper Fakultas Sains dan Teknologi (SENASAINS 2nd)

Universitas Muhammadiyah Sidoarjo

\section{REFERENSI}

[1] Downey, W. D., \& Erickson, S. P. (1996). Manajemen Agribisnis. Erlangga.

[2] Febiharsa, D., Sudana, I. M., \& Hudallah, N. (2018). Uji Fungsionalitas (BlackBox Testing) Sistem Informasi Lembaga Sertifikasi Profesi (SILSP) Batik Dengan AppPerfect Web Test Dan Uji Pengguna. JOINED Journal, 1(2), 117-126.

[3] Irawan, Y. (2017). Pengujian Sistem Informasi Pengelolaan Pelatihan Kerja UPT BLK Kabupaten Kudus dengan Metode Whitebox Testing. Sentra Penelitian Engineering dan Edukasi, 9(3), 59-63.

[4] Irmawati, D. (2011). Pemanfaatan E-Commerce Dalam Dunia Bisnis. Jurnal Ilmiah Orasi Bisnis.

[5] Mulyadi. (2008). Sistem Akuntansi. Salemba Empat.

[6] Mutiara, Achmad Benny, Muslim, A, Oswari, T. (2014). Testing Implementasi Website Rekam Medis Elektronik. Prosiding Seminar Ilmiah Nasional Komputer dan Sistem Intelijen, 8(October), 1-7.

[7] Permana, A. (2015). Sistem Informasi Kesehatan. uksw.edu.

[8] Sukrianto, D. (2017). Penerapan Teknologi Barcode pada Pengolahan Data Pembayaran Sumbangan Pembinaan Pendidikan (SPP). Jurna Intra Tech.

[9] Sutarbi, T. (2012). Analisis Sistem Informasi. Andi.

[10] Wahana Komputer. (2006). Apa \& Bagaimana E-Commerce. Andi. 